\title{
Science Outreach at the BTC Institute - Aerospace Outreach Program \& Special Initiatives Program
}

\author{
Barbara Bielec \\ BioPharmaceutical Technology Center Institute
}

\begin{abstract}
The BioPharmaceutical Technology Center Institute (BTC Institute) is a non-profit educational organization founded in 1993; located in Fitchburg, WI. During the summers of 2013 and 2014, the BTC Institute offered teacher training in biotechnology through two graduate education courses, Biotechnology: The Basics (2013 \& 2014) and Biotechnology: Beyond the Basics (2013). Teachers of a wide variety of subjects with varied levels of teaching experience were active participants in this lab-based learning that provided teachers with training, background and curriculum materials including information about NASA and biotechnology. In addition to the teacher courses, the BTC Institute in partnership with the African American Ethnic Academy, Inc. (AAEA), a Madison nonprofit organization, also offered "A Celebration of Life!, a science program for upper elementary and middle school students. The focus of the 2013 program was Energy and the focus of the 2014 program was Flight.
\end{abstract}

\section{Aerospace Outreach Program Introduction}

Biotechnology: The Basics and Biotechnology: Beyond the Basics are week long summer courses offered by the Biotechnology Technology Center Institute (BTC Institute). Biotechnology: The Basics was held during the summers of 2013 and 2014; Biotechnology: Beyond the Basics was held during the summer of 2013. The primary goal of these courses is to provide middle school and high school teachers with the training essential to implementation of a laboratory-based biotechnology curriculum. This goal served as the guide in structuring each course, as well as in designing and implementing each activity. Both courses were offered for graduate education credits through Viterbo University and Edgewood College. All three course instructors are experienced teachers of biotechnology at the secondary level.

Three objectives of the National Space Grant Program are to:

- "Encourage interdisciplinary training, research and public service programs related to aerospace." The need for quality STEM education training extends throughout many scientific disciplines, and as plans are made for humans to travel and someday live in space, biotechnology joins other technologies to support the "public service programs related to aerospace. Often students and teachers in the life sciences do not fully realize how biotechnology relates to NASA. One of the objectives for both courses was to highlight how biotechnology is and will be used in space exploration.

The BTC Institute is pleased to acknowledge the Wisconsin Space Grant Consortium Aerospace Outreach Program, the Wisconsin Space Grant Consortium Special Initiatives Program, the NASA Summer of Innovation Project, FOTODYNE Incorporated and the Wisconsin Environmental Education Board for their financial support. 
- "Recruit and train U.S. citizens, especially women, underrepresented minorities, and persons with disabilities." Enthusiastic well-trained STEM teachers are key to recruiting diverse future STEM professionals in "aerospace science and technology." Making connections between biotechnology and NASA increases the pool of teachers and students who will help meet this objective since it also brings in life science teachers and the students that they teach.

- "Promote a strong science, mathematics and technology education base from elementary through secondary levels." Biotechnology: The Basics and Biotechnology: Beyond the Basics help prepare teachers to provide "a strong STEM education base" utilizing current content and techniques. Classroom implementation of these content and techniques will enrich student learning which can "improve student academic outcomes." (National Space Grant College and Fellowship Program, 2014).

Generating student interest in further STEM education and careers, including those at NASA, will require the efforts of all STEM educators, not just physics and space science teachers. Technology training that includes discussion of NASA resources and projects will help "raise the level of exposure and interest of K-12 teachers, students, and the general public in space, aerospace, and space-related science, design, or technology and its potential benefits; and/or increase interest, recruitment, experience and training of pre-college students in the pursuit or space- or aerospacerelated science, design, or technology." Training teachers from throughout the Midwest who teach a wide variety of students also helps "Improve the STEM pipeline by including underserved and/or underrepresented students in the project; or including the teachers who specifically teach those populations." (Aerospace Outreach Program Request for Proposals 2014-2015).

Both courses included real-life examples of how biotechnology is utilized by NASA. For example, in the Summer of 2014 Dr. Eric Roden, Professor UW-Madison Department of Geoscience presented on how he uses biotechnology techniques in his bacterial research as part of the NASA funded Astrobiology Research Consortium . In addition, one of the requirements for teachers receiving a WSGC scholarship for Biotechnology: The Basics or Biotechnology: Beyond the Basics was to submit a 2-3 page summary report to the BTC Institute, at the end of the semester in which they implement discussion of NASA utilization of Biotechnology. Darcia Schweitzer, one of the 2013 WSGC teacher scholarship recipients reported the following.

Summary Report: Implementation of Classroom Discussion of NASA Utilization of Biotechnology Darcia Schweitzer, Science Teacher Dodgeland High School, Wisconsin. May 2014

Description of how a discussion of NASA utilization of Biotechnology was implemented.

Students were introduced to NASA's utilization of Biotechnology through reading the article, "Biotechnology-driven cell biology applications in microgravity: Summary of three test cases" (Kelleher, 2003). After students had read the article, we had a class discussion about the different ways biotechnology companies are cooperating with NASA to conduct research, particularly in the area of microgravity studies. Students were then asked to find another current article detailing a research project involving NASA and biotechnology. These articles were collected, copied, and distributed back, so that each student had a copy of each article. Students were asked to read the articles, and, again, participated in a class discussion of the various technologies and topics involved in biotechnology research through NASA. 
Students then received a project assignment which required them to come up with a research proposal for NASA relating to biotechnology. I gave students guidelines for writing the proposal and discussed each section required in the proposal with students. Particular emphasis was placed on the "Introduction and Literature Review" section; students were advised to put the most effort into completing a thorough review of past and current research findings related to their proposed hypothesis and experiment. Students were given a week to complete a rough draft. I read each draft and provided students with feedback about how to improve their proposal. Students were then given an additional week to develop the final draft of their proposal; this was then graded as a project, using a simple scoring rubric. Students were asked to share a brief, informal presentation of their proposal with the class.

After completing the presentations, students had an opportunity to ask questions of other students and myself. Students then received a questionnaire requesting feedback about the unit. They were asked three questions: "What have you learned about NASA's utilization of biotechnology?", "What do you still want to know about NASA's utilization of biotechnology?", and "Do you think this was a worthwhile unit? Why/why not?" They responded in writing.

\section{Student feedback on the discussion.}

Overall, students felt that this unit was worthwhile; $75 \%$ of the class responded this way on the survey. One student expressed that they "gained knowledge on [a] real world situation in which biology is a key subject for studying and making advancements for mankind." Another stated, "We got to explore outside of what we would of originally learned and we got to get in depth into it." It seems that students really appreciated the opportunity to take the content of our course and not only see its real world applications, but also attempt to develop their own ideas and hypotheses about biotechnology in space. The minority that did not find the unit worthwhile stated that they were simply disinterested in the topic.

When asked what they learned about NASA's utilization of biotechnology, many students referenced the multitude of wide-ranging experiments that have been done and could be done. "NASA has completed numerous experiments to understand how single celled organisms and plant species may [be] impact[ed] by life in space," said one student. Students also mentioned the benefit to society of many experiments that have an impact on medical knowledge and treatments. One student recognized that, "new things are being discovered, and things are progressing because of NASA's work in space...this is helping the world's medical research."

Most students enjoyed learning about this distinctive niche for biotechnology research and utilization, as evidenced by the fact that many of them responded to the survey with further questions about NASA's involvement with biotechnology. Some sample questions from the students: "I want to know what NASA goes through in order to pick an experiment to do at the ISS." "I want to know what being one of the scientists that goes up in space is like." "What does NASA intend to do in the future with biotechnology?". I think I have sparked some interest in this topic that may be long-lasting, and even persist in the choices these students make for an area of study in college or a career. I found this unit enjoyable to teach to the students because the topic kept them engaged and they were really motivated by the experimental proposal project; three students who typically do not work hard during class and complete sub-par work were able to produce proposals that demonstrated their potential. As an educator, I cannot ask for much more than that.

\section{Program Details}

Biotechnology: The Basics (2013 \& 2014) and Biotechnology: Beyond the Basics (2013) were oneweek summer courses. Representing rural, urban, and suburban school districts, the attendees were teachers of a variety of subjects, including: middle school science, biology, biotechnology, agriculture, and chemistry. Class participants included teachers who had no previous training in biotechnology, as well as very experienced secondary teachers looking to update their knowledge of scientific content and techniques. Some of the teachers currently teach an independent biotechnology course; others incorporate biotechnology curricula within other life science, 
chemistry or agriculture classes. Several teachers were looking for information to help them design and implement a biotechnology course for the first time.

For both courses, teacher participants were recruited through direct contact at the BTC Institute and a variety of teacher conferences; emails and electronic postings to several list-servs and websites; direct recommendation from UW-River Falls Agriculture Education Professor Timothy Buttles; and course listings in the Viterbo University and Edgewood College summer catalogs.

Table 1: Participants in Biotechnology: The Basics and Biotechnology: Beyond the Basics

\begin{tabular}{|c|c|c|c|c|}
\hline Teacher Course & $\begin{array}{c}\text { Total } \\
\text { Participants }\end{array}$ & $\begin{array}{c}\text { High School } \\
\text { Science } \\
\text { Teachers }\end{array}$ & $\begin{array}{c}\text { Agriculture Teachers. } \\
\text { Often teach both high } \\
\text { school and middle } \\
\text { school }\end{array}$ & $\begin{array}{c}\text { Other. } \\
\text { Includes } \\
\text { middle school } \\
\text { teachers }\end{array}$ \\
\hline $\begin{array}{c}\text { Biotechnology: } \\
\text { The Basics 2013 }\end{array}$ & 9 & 3 & 4 & 2 \\
\hline $\begin{array}{c}\text { Biotechnology: } \\
\text { Beyond The Basics }\end{array}$ & 7 & 5 & 1 & 1 \\
\hline $\begin{array}{c}\text { 2013 } \\
\text { Biotechnology: }\end{array}$ & 7 & 5 & 2 & 0 \\
\hline Basics 2014 & 23 & 13 & 7 & 3 \\
\hline
\end{tabular}

Attendance in these courses was largely due to scholarship funding provided by the Wisconsin Space Grant Consortium, the BTC Institute and FOTODYNE, Inc. Professional development funding is increasingly difficult for teachers to obtain, and the BTC Institute and the teachers who took the courses are very grateful for this support.

Topics and laboratory activities for Biotechnology: The Basics included: use of micropipettes, agarose gel electrophoresis, DNA extraction, restriction enzyme digestion, polymerase chain reaction (PCR), bacterial transformation, bioethics, genetic counseling, biotechnology and NASA, stem cells, biofuels and the Great Lakes Bioenergy Research Center, and careers and training in biotechnology.

Topics and laboratory activities for Biotechnology: Beyond the Basics included: PCR and transformation of the PTC gene, genetic identity testing, microarrays, science and social media, protein purification and detection, immunology, bioinformatics, biotechnology and NASA, bioprospecting and the Great Lakes Bioenergy Research Center, and, training and careers in biotechnology.

Implementation was consistently emphasized. How would teachers apply what they learned in their own classrooms? Resources included a comprehensive course binder for each teacher; laboratory protocols, classroom activities and power point presentations on a flash drive for each teacher; daily discussion and review of course topics and resources; and discussion of funding and equipment sources and tips for successful grant writing.

Each day teachers wrote a reflection detailing how they would integrate material into their curriculum and the challenges that they might face, including the resources they would need. These reflections were discussed the next day with the entire group. As a final project, each teacher 
had to design and present a detailed and personalized curricular unit (lesson plan) that they intend to use with their students.

\section{Results}

Course evaluations were extremely positive for all three courses. For example, the 2014 Biotechnology: the Basics course evaluations included the following comments:

- I can't single out any [workshops] that were the most useful. I came here wanting to gain knowledge \& all the workshops did that.

- I am very grateful for the scholarship, materials and the 2 awesome teachers we had. I also was really pleased with the low student/teacher ration. Also I was very happy to get my questions answered.

- I thought this was great. I had limited knowledge of the topic and fell good about where I am at now. I wouldn't change anything.

- I thought it [the course] was excellent, I really enjoyed the mix - lab discussion, content, guest speakers, etc., etc.

- Loved all the labs \& hands-on activities.

- The course was outstanding - great feedback daily \& all questions were answered. Review sheets each day were excellent way to received feedback.

- I received a plethora of resources, techniques and ideas!! Excellent week! Best weeklong class taken!! Thanks for everything!

Course evaluations also offered suggestions to improve the courses:

- More time to communicate with participants.

- $\quad$ [some] workshops were helpful but need to be a little shorter in length.

- Color code binder to find materials easier.

- Consider offering something for middle school teachers.

- Perhaps the lab protocols could be broken down into a flow-chart for the pre-lab discussion/directions.

- More structured teacher "share time".

Course evaluations and daily reflections are used to improve courses year to year, as well as to address questions and concerns throughout the course. Next year several of the suggestions will be incorporated.

\section{Conclusion}

The enthusiasm demonstrated by our attendees is always inspiring. It consistently and clearly demonstrates the need for high quality professional development opportunities that have immediate relevance to the classroom. As stated by the National Science Board/National Science Foundation (NSB/NSF) in A National Action Plan for Addressing the Critical Needs of the U.S. Science, Technology, Engineering, and Mathematics Education System: "The United States possessed the most innovative, technologically capable economy in the world, and yet its science, technology, engineering, and mathematics (STEM) education system is failing to ensure that all American students receive the skills and knowledge required for success in the $21^{\text {st }}$ century workforce." In the action plan's description of implementation it elaborates: "stakeholders should create professional development opportunities that deepen teachers' content knowledge, inquiry experiences, pedagogical skills, and understanding of instructional materials and their use in the classroom. Retaining high quality STEM teachers depends on facilitating access to opportunities for professional development and intellectual growth throughout their careers." (NSB/NSF 2007) 
We are committed to offering quality professional development in STEM for teachers so that their students develop the STEM skills and knowledge needed for future success. We will continue to seek grant opportunities and new partnerships that will enable us to fund teacher scholarships and provide teachers with much-needed resources. The support provided by the Wisconsin Space Grant Consortium to design and implement these courses is greatly appreciated. The donations of instructor time and materials from Fotodyne, Promega, the Morgridge Institute for Research, Meriter Hospital, Madison Area Technical College, the Great Lakes Bioenergy Research Center and the UW-Madison Department of Geoscience Astrobiology Research Consortium are also key to our success. These partnerships, along with the options to receive graduate education credits through Viterbo University and Edgewood College, ensure the continuation of these essential opportunities for professional development.

\section{Special Initiatives Program \\ Introduction}

The primary goal of "A Celebration of Life" is to support the continued development of African American and other students' interest in science, and to provide them with tools for success in school. A long-term goal continues to be increasing the number of minority students who successfully complete high school science courses, and who may eventually choose to pursue science, technology, engineering and math (STEM) careers. Extensive efforts are made to ensure participation of students from economically challenged families through the provision of scholarships and transportation.

\section{Program Details}

The program themes for 2013 and 2014 were Energy and Flight, respectively. The two-week weekday morning programs were held in June and July, the first session was for elementary students grades 3-5, the second session was for middle school students grades 6-8. For both sessions, hands-on activities, in outdoor, classroom and laboratory settings, were designed to engage students' interest in science and STEM careers. This was accomplished through a series of activities about energy, flight, NASA projects and African American STEM professionals. Program activities reflect the Wisconsin Model Academic Standards for Science, which follow the form and content of the National Science Education Standards. Many of the educational activities were from the NASA Summer of Innovation Project (http://www.nasa.gov/offices/education/programs/national/summer/home/index.html, 2013 ).

Fifty-eight percent of the student participants were African American, and 69\% of all participants belong to an underrepresented minority group. Many participants received scholarships and transportation to facilitate their participation in the program. A total of 72 students: 36 girls (50\%) and 36 boys $(50 \%)$, participated in developmentally appropriate learning. 


\begin{tabular}{|l|c|c|c|c|c|c|}
\hline Program & $\begin{array}{c}\text { Total } \\
\text { Participants }\end{array}$ & Girls & Boys & $\begin{array}{c}\text { African- } \\
\text { American }\end{array}$ & Hispanic & Other \\
\hline $\begin{array}{l}2013 \text { Energy } \\
\text { Elementary }\end{array}$ & 19 & 8 & 11 & 11 & 0 & 8 \\
\hline $\begin{array}{l}\text { 2013 Energy } \\
\text { Middle School }\end{array}$ & 18 & 10 & 8 & 12 & 1 & 5 \\
\hline $\begin{array}{l}\text { 2014 Flight } \\
\text { Elementary }\end{array}$ & 14 & 6 & 8 & 7 & 3 & 4 \\
\hline $\begin{array}{l}\text { 2014 Flight } \\
\text { Middle School }\end{array}$ & 21 & 12 & 9 & 12 & 4 & 5 \\
\hline Total & 72 & 36 & 36 & 42 & 8 & 22 \\
\hline
\end{tabular}

Specific topics for the summer 2013 Energy! and 2014 Flight! programs are listed below and many of the educational activities used were designed by NASA.

2013 Energy!

- types of energy

- energy for plants and animals

- renewable and nonrenewable sources of energy

- energy conservation

- current NASA projects related to energy, including space exploration

- historic and contemporary African American STEM professionals, including those affiliated with NASA

2014 Flight!

- basic principles of flight

- how birds fly

- constructing/testing aircraft and rockets

- current NASA projects related to flight, including space exploration

- careers in aviation

- historic and contemporary African American (STEM) professionals, including those affiliated with NASA

Each session also included a field trip and concluded with student presentations of selected activities to their peers, family members and other adult guests on the last day of each session. Students also shared their posters of African American STEM Professionals.

\section{Results}

Pretests and post-tests are administered as part of each AAEA/BTC Institute summer science program as one indicator of students' learning. Overall, both elementary and middle school students showed an increased knowledge about energy, flight and African American STEM professionals. Some example questions and results are listed below.

In 2013 elementary students were asked to "Draw a food chain that shows how energy is transferred." On the pre-test, $81 \%(13 / 16)$ left this blank. On the elementary post-test, $67 \%(12 / 16)$ students could draw a food chain correctly and the other $33 \%$ could draw a food chain with some errors. 
In 2013 middle school students were prompted: "The person in this picture is a STEM professional. What does STEM stand for?" On the pre-test, 73\% (11/15) students left this prompt blank or gave an incorrect answer; on the post-test, $100 \%(16 / 16)$ could answer correctly.

Comments from the students who participated also speak to the impact of the program. When asked on the 2013 post-test, "Would you like to become a STEM Professional when you grow up? Why or why not?" elementary responses (spelling corrected) included:

- I would love to be a STEM Professional because I now know a lot about STEM.

- Yes, because I really like science.

- Sure why not I'd think it would be fun.

- I would love to be a STEM professional because it seems fun and I love helping people.

- Yes I would, because I will be helping the economy and create better energy sources.

- I would because I want to be a science leader and I love science.

On the 2014 elementary tests students were asked to "List any African American aviators (pilots or astronauts) or scientists, engineers or mathematicians that you know about." Space was given for four answers. On the pretest only 1/13 (8\%) students answered with the name of one African American STEM professional, the rest left the question blank. On the post-test all students (100\%) listed four African American STEM professionals we had featured.

On the 2014 middle school tests students were asked, with an airplane diagram, to "Fill in the names of the 4 forces that act on an airplane." On the pretest only 4/19 (21\%) students could label either three or four forces correctly, on the post-test 14/16 (88\%) could label all four forces correctly.

On the 2014 pretest and post-test middle school students were also asked: "Would you like a career in aviation or at NASA? Why or why not? Results are lists are listed below, spelling corrected.

Table 3: A Celebration of Life XIX: Flight! Middle School Responses to the prompt: "Would you like a career in aviation of at NASA? Why or why not?

\begin{tabular}{|l|c|c|}
\hline \multicolumn{1}{|c|}{ Response } & Pretest & Post-test \\
\hline Yes & 4 & 9 \\
\hline Maybe/ Don't know & 4 & 1 \\
\hline No & 7 & 6 \\
\hline No answer & 1 & 0 \\
\hline Total & 16 & 16 \\
\hline
\end{tabular}

- Aviation because they have good planes and they have candy but you can choose to be a pilot or not.

- Yes, because I'm fascinated with things that fly.

- I would like a job at NASA because I am more interested in Technology \& Engineering.

- I think I would definitely consider it because I would love to experience actually flying, but I would probably be too scared.

- Yes, because now I know there are more jobs than astronauts, and some that I might like.

- Yes so I can fly in a plane with comfortable seats and get paid a lot of money.

- No because I really want to be a bone doctor and artist.

- Yes, because I always want to fly and see what space is like (what I looks like and the feeling of no gravity.

- No. I don't like to fly because I'm afraid of heights.

- No, I like the ocean better.

- I wouldn't be too interested in a career of aviation but working at NASA seems cool and awesome.

- I would like a career in NASA because I really wanted to go to space. 
- I would want to be a pilot because it's fun, easy (except for bad weather and in the dark) and in the sky it looks like you cans see the whole world!

Scientific content knowledge can be measured by the pretests and post-tests, providing information regarding one aspect of program assessment. Another key indication of success is the number of students who had participated in previous AAEA/BTC Institute programs, or who had family members who were previous participants. In the 2013 and 2014 summer programs, participants included 72 elementary and middle school students total. Of those 72 students, 53\% (38/72) had previously participated, or have had family members who have participated. In the 2014 middle school program, of the 21 participants, $62 \%$ (13/21) had previously participated, or had family members who had participated. Eight of those 13 previous participants, all members of underrepresented minority groups, have participated for $3+$ years!

The return rate of students, along with excellent attendance throughout both sessions, is solid evidence that this program is valued by the participants and their families. When students return for the third, fourth, fifth or sixth year, it is a strong indication of their interest in science programming.

\section{Conclusion}

The National Science Foundation (NSF) report, Women, Minorities, and Persons with Disabilities in Science and Engineering: 2011, noted that: "Underrepresented minorities [blacks, Hispanics, and American Indians] share of science and engineering bachelor's and master's degrees have been rising over the two decades since 1989, with shares of doctorates in these fields flattening after 2000. The greatest rise in science and engineering bachelor's degrees earned by underrepresented minorities has been in the social, computer, and medical sciences fields of study." However, this increase in STEM degrees still does not show equivalency with the population percentage of underrepresented minority groups in the U.S. population. From data presented in the NSF report African Americans comprised only 3\% of the "Scientists and engineers in science and engineering occupations: 2006." The report concluded that: "The science and engineering workforce is largely white and male. Minority women comprise fewer than 1 in 10 employed scientists and engineers." (NSF, Women, Minorities, and Persons with Disabilities in Science and Engineering: 2011) Supporting African American educational opportunities in science is essential to helping increase the number of African American students who will ultimately go into baccalaureate and graduate programs in science.

A National Science Teachers Association feature article about science education programs that successfully engage underrepresented students describes the importance of culturally relevant content: "Teachers should discuss African-American scientists throughout the course, not just during Black History Month...Although textbooks may still lack adequate connections between science content and minority scientists, the internet is a great source to find individuals linked to specific stages of scientific development. Minority students will identify with these role models, and thus begin to personalize the science concepts and consider careers in science." (Bardwell and Kincaid, 2005). The AAEA/BTC Institute programs will continue to focus on African American STEM professional role models to help inspire students.

This approach is in alignment with the goal and objectives of the National Space Grant Program, 2010-2014. "The goal of the Space Grant Program is to contribute to the nation's science enterprise by funding education, research, and informal education projects through a national network of 
university-based Space Grant consortia." One of the objectives of the Space Grant Program is to: "Promote a strong science, technology, engineering, and mathematics education base from elementary through secondary levels while preparing teachers in these grade levels to become more effective at improving student academic outcomes." A second objective is to: "Recruit and train U.S. citizens, especially women, underrepresented minorities, and persons with disabilities, for careers in aerospace science and technology." (National Space Grant College and Fellowship Program [Space Grant] 2010-2014).

The support provided by the Wisconsin Space Grant Consortium helps the A Celebration of Life! summer science program meet both of these objectives, and the overall goal of the Space Grant Program. A Celebration of Life! has helped provide a "strong science, technology, engineering and mathematics education base" for both upper elementary and middle school secondary students. The exploration opportunities provided by the summer program enrich and enhance students' scientific knowledge and associated skills. It is also essential for students to see themselves in those roles. Learning about historic and contemporary African American STEM professionals as part of an exciting hands-on science program assists in developing a diverse work force of problem solvers, scientists, inventors and engineers for "careers in aerospace science and technology."

\section{References}

Aerospace Outreach Program Request for Proposals 2014-2015. Available at http://www.uwgb.edu/WSGC/k12/announcements/ao.aspx

Bardwell, Genevieve and Kincaid, Eric. The Science Teacher, February 28, 2005. A Rationale for Cultural Awareness in the Science Classroom. http://www.nsta.org/publications/news/story.aspx?id=50285\&print=true

NASA Summer of Innovation Project, 2013. Available at http://www.nasa.gov/offices/education/programs/national/summer/education_resources/index.html

National Science Foundation, Division of Science Resources Statistics. 2011. Women, Minorities, and Persons with Disabilities in Science and Engineering: 2011. Special Report NSF 11-309. Arlington, VA. Available at http://www.nsf.gov/statistics/wmpd/.

National Science Board / National Science Foundation. A National Action Plan for Addressing the Critical Needs of the U.S. Science, Technology, Engineering, and Mathematics Education System, October 30, 2007.

http://www.nsf.gov/nsb/publications/2007/nsb1007.pdf

National Space Grant College and Fellowship Program (Space Grant), 2014.

http:/www.nasa.gov/offices/education/programs/national/spacegrant/about/index.html 